\title{
Molecular and Biochemical Study of Superoxide Dismutase Gene Polymorphisms in Egyptian Patients with Type 2 Diabetes Mellitus with and without Retinopathy
}

\author{
Ahmed A. Sayed ${ }^{1 *}$, Yousef Aldebasi ${ }^{2}$, Sanaa O. Abd-allah ${ }^{3}$, \\ Saad M. El Gendy ${ }^{4}$, Amr Saad Mohamed ${ }^{3}$ and Mona S. Abd EI-Fattah ${ }^{5}$ \\ ${ }^{1}$ Clinical Pathology Department (Biochemistry), Al-Azhr University, Egypt. \\ ${ }^{2}$ Optometry Department, Applied Medical Science College, Qassim University, KSA. \\ ${ }^{3}$ Chemistry Dept., Cairo University, Egypt. \\ ${ }^{4}$ Optometry Department, Applied Medical Science College, Qassim University, KSA. \\ ${ }^{5}$ Immunology and allergy center, Al-Azhr University, Egypt.
}

Authors' contributions

This work was carried out in collaboration between all authors. Authors YA and SMEG designed the study performed, wrote the protocol. Authors AAS, MSAEF providing all possible laboratory facilities to accomplish the practical part of this study. Authors SOA and

ASM managed the analyses of the study fruitful discussion and profound revision of the results and discussion of the manuscript. All authors read and approved the final manuscript.

Research Article
Received $23^{\text {th }}$ October 2012 Accepted $4^{\text {th }}$ November 2012 Published $2^{\text {nd }}$ April 2013

\section{ABSTRACT}

Aims: This study aims to determine the antioxidant enzyme EC-SOD polymorphisms in Egyptian patients with type 2 diabetes mellitus with and without retinopathy, and its association with other biochemical changes to assess whether decreased SOD activity is associated with the development of diabetic complications.

Study Design: Cross-sectional study.

Place and Duration of Study: Department of Medicine Al-Hussein University Hospital, Cairo, Egypt, between May 2010 and April 2011.

Methodology: The present study investigated the relationship among diabetes mellitus, lipid profiles, SOD activity, ESR, and CRP in the blood of 40 patients with type 2 diabetes with and without retinopathy and 20 healthy control subjects. The mean age of the diabetic 
patients was similar to that of control. The mean duration of the disease was $3.53 \pm 1.17$ years (1-5 years) in patients with type 2 diabetes without retinopathy and $18.7 \pm 3.1$ with retinopathy. Also we studied Arg213Gly dimorphism of the EC-SOD gene in type 2 diabetic patients with and without retinopathy and control persons using the PCR technique.

Results: Superoxide dismutase (SOD) level was significantly decreased in diabetics and more markedly decrease in those with retinopathy. Total cholesterol (CHOL), triglyceride (TG) and low-density lipoprotein-cholesterol (LDL-c) levels were significantly increased in diabetics and more markedly increased in those with retinopathy compared with the control level. Genotype distribution of the EC-SOD in diabetic patients with and without retinopathy differed from normal individuals, as the argentines-to-glycine amino acid substitution was higher in diabetic patients compared with the normal individuals.

Conclusion: The present study revealed that hyperglycemia produced marked oxidation impact as evidenced by a significant increase in lipid profile, lipid per oxidation products, as well as a significant decrease in the total SOD activity. Moreover, it showed that the genotype distribution of the EC-SOD was differed as the arginine-to-glycine amino acid substitution was higher in diabetic patients with and without retinopathy compared with the control individuals. This report emphasizes the important role of superoxide dismutase and its genotype distribution in diabetic patients with and without retinopathy, and hence the need for antioxidant supplements to delay the severity of diabetic retinopathy.

Keywords: Lipid per oxidation; superoxide dismutase; polymorphisms; diabetes; retinopathy.

\section{INTRODUCTION}

Diabetes is recognized as one of the leading causes of morbidity and mortality in the world. About $2.5-3 \%$ of the world's population suffers from this disease, a proportion which, in some countries, can reach $7 \%$ or more [1]. Diabetes mellitus type 2 - formerly non-insulindependent diabetes mellitus (NIDDM) or adult-onset diabetes - is characterized by high blood glucose in the context of insulin resistance and relative insulin deficiency [2]. Insulin resistance means that body cells do not respond appropriately when insulin is present. Type 2 diabetes is due to a combination of lifestyle and genetic factors [3,4]. It is a wellestablished fact that diabetes mellitus is a risk factor for cardiovascular disease which is leading cause of death in diabetic population [5]. Fasting blood sugar means that the patient hasn't eaten for about eight hours before he has the test done.

Fasting blood sugar's really very important particularly in diagnosing diabetes and oftentimes in therapeutic management, and it's important because the system is clean of at least any sugar he has eaten prior to that test, The post-prandial blood sugar is a measure of the patient blood glucoses after he has eaten. This number is highly variable and dependent on what he has taken in. For example, if he has had a meal that's high in carbohydrate, his blood sugars will go up quickly but may come down more rapidly. If he has had a meal that's high in protein or fat, it may stay up longer but it tends to rise more slowly. The goal is that the two-hour reading after meal is less than $180(\mathrm{mg} / \mathrm{dL})$.

Hyperglycemia-induced intramural pericyte death and thickening of the basement membrane lead to incompetence of the vascular walls. These damages change the formation of the blood-retinal barrier and also make the retinal blood vessels become more permeable [6]. All people with diabetes mellitus are at risk. The longer a person has diabetes, the higher the risk of developing some ocular problem. Between 40 to 45 percent of Americans diagnosed with diabetes have some stage of diabetic retinopathy [7]. 
Diabetic retinopathy (DR) has chronic progression, with early nonproliferative diabetic retinopathy (NPDR) being characterized by increased vessel permeability, micro aneurysms, and capillary loss [8]. Ensuing retinal ischemia triggers proliferative DR (PDR), with neovascularization leading to fibro vascular changes, retinal traction, detachment, and blindness. Loss of cells in the neural retina as well as glial changes occurs early in DR and often precedes vascular disease. Diabetic retinopathy is the most common diabetic eye disease and a leading cause of blindness in adults. It is caused by changes in the blood vessels of the retina. Diabetic retinopathy is an ocular manifestation of systemic disease which affects up to $80 \%$ of all patients who have had diabetes for 10 years or more [9]. Despite these intimidating statistics, research indicates that at least $90 \%$ of these new cases could be reduced if there was proper and vigilant treatment and monitoring of the eyes [10].

Diabetic hyperglycemia has been reported to promote the overproduction of reactive oxygen species such as superoxide, causing hyperglycemic vascular damage in vivo and in vitro. Superoxide is secreted from various cells in the vascular system and is implicated in the insulin-resistant state. The increase in superoxide may contribute to oxidative processes in the vessel wall, such as induction and enhancement of cell membrane lipid per oxidation and oxidation of low-density lipoprotein (LDL). Moreover, superoxide reacts extremely rapidly with nitric oxide (NO), which modulates vasomotor tone, inhibits platelet-and leukocyte-aggregation, and produces peroxynitrite. An increase in superoxide dismutase (SOD) has been reported to attenuate diabetic vascular dysfunction [11].

Superoxide dismutase (SOD) is a family of ubiquitous antioxidant metalloproteinases that catalyze the conversion of superoxide anion radicals to hydrogen peroxide and molecular oxygen [12]. The enzymatic disproportionation or dismutation (Equation 1) of superoxide free-radical anion species by superoxide dismutase (SOD) was characterized by McCord and [13]

$$
\cdot \mathrm{O}_{2}^{-}+\cdot \mathrm{O}_{2}^{-}+2 \mathrm{H}+\stackrel{\mathrm{SOD}}{\longrightarrow} \mathrm{H}_{2} \mathrm{O}_{2}+\mathrm{O}_{2}
$$

Since that discovery, a total of three genetically distinct mammalian isoforms of SOD have now been reported. SOD1, a copper- and zinc-containing SOD (CuZn-SOD), is localized primarily to cytoplasmic and nuclear compartments. Its mapping to chromosome 21 was important for the subsequent successful genetic linkage of mutations in SOD1 to hereditary forms of familial amyotrophic lateral sclerosis. SOD2, a manganese-containing SOD (MnSOD) is linked to human Chromosome 6 and is found predominantly in mitochondria. SOD2 has been shown to play a major role in promoting cellular differentiation, protecting against hyperoxic-induced pulmonary toxicity, and providing cellular resistance to cytotoxicity by tumor necrosis factor (TNF). By contrast, SOD3, or extracellular superoxide dismutase (ECSOD), is the predominant extracellular antioxidant enzyme. EC-SOD has been found in serum, cerebrospinal, ascetic, and synovial fluids. In some human tissues such as uterus, umbilical cord, placenta, and arteries, EC-SOD enzyme activity equals or exceeds that of CuZn-SOD and Mn-SOD. An EC-SOD-like activity has been identified in every mammal examined thus far [14]. Several reports, furthermore, suggest that the EC-SOD gene is one of candidate genes for type 2 diabetes.

The human EC-SOD gene is located in chromosome 4 and consists of three exons. The 720 bp coding region is located entirely within the exon 3 [15]. EC-SOD is a secretory glycoprotein with an affinity for heparan-like substances, and it is the principal enzymatic scavenger of superoxide in the extracellular space. It has been shown that $99 \%$ of the enzyme is bound to heparan sulfate proteoglycans in vascular walls and to a lesser extent 
within the interstitium and $1 \%$ is contained within the circulation in equilibrium between the plasma phase and the glycocalyx of the endothelium. Molecular genetic studies have shown that a single-base substitution causing exchange of glycine for arginine-213 (Arg213Gly) in the heparin binding domain of EC-SOD is associated with markedly increased plasma concentrations of the enzyme $[16,17]$.

In this study, we investigated the role of EC-SOD gene mutation in Egyptian patients with type 2 diabetes mellitus with and without retinopathy, and its association with other biochemical changes.

\section{MATERIALS AND METHODS}

\subsection{Materials}

The chemicals used were high analytical grade, purchased from Promega Corporation (Madison, WI, USA), Stratagene (La Jolla, CA, USA), Sigma Chemical Co. (St. Louis, MO, USA), dp- International and Egyptian Company for Biotechnology, unless otherwise stated.

\subsection{Subjects and Samples Collection}

This study was conducted on 60 individuals who fulfilled the World Health Organization criteria for diabetes. They were recruited from the Department of Internal Medicine, AlHussein University Hospital, Cairo, Egypt They categorized into three groups: (1) healthy individuals as normal control ( 20 volunteers, 8 men and 12 women), the mean age was $(43.05 \pm 4.07)$ years [mean $\pm S D$ ], range (37-56 years), (2) twenty patients were diagnosed as type 2 diabetes without retinopathy ( 10 men and 10 women; age $47.6 \pm 3.83$ years [mean \pm SD], range (39-58 years) and (3) twenty patients were diagnosed as type 2 diabetes with retinopathy ( 13 men and 7 women; age $46.34 \pm 2.68$ years [mean \pm SD], range $43-59$ years). Approximately $4 \mathrm{ml}$ of blood was drawn from the vein of each participant after informed consent. The healthy individuals indicated normal plasma glucose level and no glycosuria. The blood samples immediately after collections were divided into: (1) Heparinzed blood for HbA1c assay and genomic DNA extraction (2) plasma for the biochemical assay. Written consent was obtained from the participants after they were given an explanation of the study details. A complete history of each participant, with respect to age, gender, clinical symptoms, diabetes type and duration, and socioeconomic background, was collected using a well designed questionnaire. The funds of each subject were evaluated by both direct and indirect ophthalmoscopy, and PDR was defined and classified according to [18].

The exclusion criteria were: Renal and Liver disease, Bronchial asthma, Diabetes Insipidus, Thyroid disease, Obesity and type of diabetic therapy.

\subsection{Laboratory Measurements}

\subsubsection{Determination of blood sugar level and lipids profile}

Serum glucose, total cholesterol $(\mathrm{CHOL})$ and triglyceride $(\mathrm{TG})$ levels were determined by glucose oxidase, CHOD-PAP and GPO-PAP enzymatic test kits supplied by Spectrum diagnostics, Egypt. HDL-c was determined by precipitation of LDL-C and VLDL in the presence of phosphotungstic acid and magnesium chloride (HDL-cholesterol precipitating 
reagent from Spectrum diagnostics, Egypt). LDL-C was calculated according to the Friedewald formula [19].

\subsubsection{Determination of glycated hemoglobin (HbA1c)}

Glycated hemoglobin $\mathrm{A} 1 \mathrm{c}(\mathrm{HbA} 1 \mathrm{c})$ was determined according to the method of [20]: using STNBIO laboratory kit (Germany). The results were expressed as \%.

\subsubsection{Determination of ESR and CRP}

Erythrocytic sedimentation rate (ESR) was determined according to the method described by [21] while the serum CRP concentration was determined according to the slide agglutination method described by [22] using a commercial assay kit (Diamond diagnostics, Egypt).

\subsubsection{Superoxide dismutase (SOD) assay}

Total SOD activity was performed in serum by quantifying the inhibition of NBT transformation to formazan, using the method of [23]. The SOD activity is calculated by measuring the amount of generated superoxide anions scavenged by SOD (the inhibitory level of formazan color development). 1 unit ( $50 \%$ inhibitory level) corresponds to $7.47 \mu \mathrm{g} / \mathrm{ml}$ of the reaction mixture of SOD. The results were expressed as $\mathrm{U} / \mathrm{ml}$.

\subsubsection{DNA analysis}

Genomic DNA was extracted from the whole blood using QIAamp Blood Kit (QIA) (Qiagen, Germany). Polymorphic region was amplified by polymerase chain reaction (PCR) in a $50 \mu \mathrm{l}$ reaction mixture consisting of $10 \mathrm{mM}$ Tris- $\mathrm{HCl}(\mathrm{pH} 8.8), 50 \mathrm{mM} \mathrm{KCl}, 1.5 \mathrm{mM}$ magnesium chloride, $0.1 \%$ Tween-20, $10 \%$ dimethyl sulfoxide, $0.2 \mathrm{mM}$ of each dNTP, 5 pmol of each primer SOD3-213F 5'-GGCTGGCCTGCTGCGTGGTGG-3' and SOD3-213R 5'CCTTGCACTCGCTCTCGCGCG-3', $100 \mathrm{ng}$ of genomic DNA, and 2.5 units of Taq polymerase. PCR was carried out in a the heating block in the DNA thermal cycler (Omnigene, Hybaid, 01747) with 35 cycles of denaturation for 1 min at $94^{\circ} \mathrm{C}$, annealing for 1 min at $65^{\circ} \mathrm{C}$, and extension for $1 \mathrm{~min}$ at $72^{\circ} \mathrm{C}$. To detect the Arg213Gly polymorphism of the EC-SOD gene the PCR product was digested with restriction endonuclease Eco52I (Fermentas, Lithuania) in Eco52I specific buffer. For digestion, $10 \mu \mathrm{l}$ of PCR product were added to 16-17 $\mu \mathrm{l}$ of nuclease-free water, $2 \mu \mathrm{l}$ of $10 \mathrm{X}$ recommended buffer for restriction enzyme and 1-2 $\mu \mathrm{l}(10-20 \mathrm{u})$ of restriction end nuclease Eco52l,and mixed well then incubated at $37^{\circ} \mathrm{C}$ for 2 hours. Digested DNA products were separated by electrophoresis in a $3 \%$ agarose gel with ethidium bromide [24].

\subsubsection{Statistical analysis}

Statistical analysis was performed using the SPSS/PC statistical program (version 12.0 for Windows). Descriptive results of continuous variables are expressed as means \pm S.D. Differences in mean values between groups were assessed by the Student's $t$ test. Relationships between two quantitative variables were assessed by Pearson's correlation coefficient. The criterion for significance was $p<0.05$. 


\section{RESULTS AND DISCUSSION}

\subsection{Results}

\subsubsection{Clinical and biological analysis}

Clinical and biological data of healthy and diabetic subjects with and without retinopathy are summarized in Table 1.

Fig. 1 showed abnormal Fasting blood glucose in diabetic group without retinopathy $(119.40 \pm 16.02)$ and in diabetic group with retinopathy $(142 \pm 19.1)$ when compared with control group (78.11 \pm 4.82$)$, postprandial blood glucose in diabetic group without retinopathy $(153.43 \pm 29.47)$ and in diabetic group with retinopathy $(223 \pm 21.3)$ when compared with

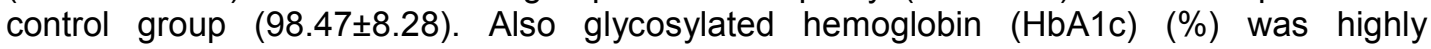
significantl increased in diabetic group without retinopathy (8.20 \pm 1.30$)$ and in diabetic group with retinopathy $(10.2 \pm 2.1)$ when compared with control group $(4.67 \pm 0.32)$.

Diabetic patients with and without retinopathy showed abnormal lipids profile with a significantly higher serum level of $\mathrm{CHOL}(\mathrm{mg} / \mathrm{dl})(311.2 \pm 23.82)$ and $(209.83 \pm 22.72)$ respectively. They showed a significantly higher serum level of TG (mg/dl) $(192.4 \pm 18.11)$, (171.32 \pm 16.86$)$, respectively. Also they showed a significantly higher serum level of LDLCholesterol (mg/dl) $(166.6 \pm 22.61),(143.73 \pm 18.96)$ respectively. Whereas they showed a significantly lower concentration of HDL-Cholesterol (mg/dl), (34.62 \pm 3.2$)$, (37.19 \pm 3.18$)$ respectively compared to the healthy subjects CHOL $(164.73 \pm 14.49)$, TG $(123.6 \pm 29.17)$,

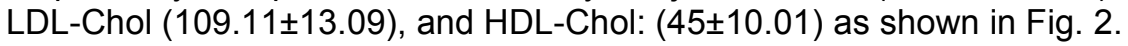

Moreover, the diabetic patients with and without retinopathy have increased inflammatory markers (ESR\&CRP) with a significantly higher level of ESR $(\mathrm{mm} / \mathrm{h})(19.3 \pm 6.1),(12.64$ $\pm 9.08)$, respectively and significantly higher level of CRP ( $g / L)(7.6 \pm 1.23),(5.90 \pm 1.72)$ respectively compared with the healthy subjects (ESR: $5.2 \pm 2.54$ and CRP: $3.04 \pm 1.59$ ), respectively.

SOD activity $(\mathrm{U} / \mathrm{ml})$ showed a significantly decrease in diabetic patients without retinopathy and highly significant decrease in diabetic patients with retinopathy $(2.1 \pm 0.22),(1.5 \pm 0.12)$ respectively, compared with the control level $(3.03 \pm 0.31)$. 
Table 1. Clinical and biological parameters in diabetic patients and control subjects

\begin{tabular}{llll}
\hline $\begin{array}{l}\text { Group } \\
\text { Parameter }\end{array}$ & Control & $\begin{array}{l}\text { Diabetic without } \\
\text { retinopathy }\end{array}$ & $\begin{array}{l}\text { Diabetic with } \\
\text { retinopathy }\end{array}$ \\
\hline Number & 20 & 20 & 20 \\
Female/Male & $8 / 12$ & $10 / 10$ & $13 / 7$ \\
Age (years) & $43.05 \pm 4.07$ & $44.6 \pm 3.83$ & $46.34 \pm 2.68$ \\
Duration of diabetes (years) & $\ldots \ldots \ldots \ldots \ldots$ & $4.65 \pm 1.27$ & $18.7+3.1$ \\
FBS $(\mathrm{mg} / \mathrm{dl})$ & $78.11 \pm 4.82$ & $119.40 \pm 16.02^{* *}$ & $142 \pm 19.1^{* *}$ \\
PPS $(\mathrm{mg} / \mathrm{dl})$ & $98.47 \pm 8.28$ & $153.43 \pm 29.47^{* *}$ & $223 \pm 21.3^{* *}$ \\
HbA1c $(\%)$ & $4.67 \pm 0.32$ & $8.20 \pm 1.30^{* *}$ & $10.2 \pm 2.1^{* *}$ \\
ESR(mm/h) & $5.2 \pm 2.54$ & $12.64 \pm 9.08^{*}$ & $19.3 \pm 6.1^{*}$ \\
CRP(mg/L) & $3.04 \pm 1.59$ & $5.90 \pm 1.72^{*}$ & $7.6 \pm 1.23^{* *}$ \\
CHOL $(\mathrm{mg} / \mathrm{dl})$ & $164.73 \pm 14.49$ & $209.83 \pm 22.72^{*}$ & $311.2 \pm 23.82^{* *}$ \\
TG(mg/dl) & $123.6 \pm 29.17$ & $171.32 \pm 16.86^{*}$ & $192.4 \pm 18.11^{* *}$ \\
HDL-c(mg/dl) & $45 \pm 10.01$ & $37.19 \pm 3.18^{*}$ & $34.62 \pm 3.2$ \\
LDL-c(mg/dl) & $109.11 \pm 13.09$ & $143.73 \pm 18.96^{*}$ & $166.6 \pm 22.61^{* *}$ \\
SOD activity $(\mathrm{U} / \mathrm{ml})$ & $3.03 \pm 0.31$ & $2.1 \pm 0.22^{*}$ & $1.5 \pm 0.12^{* *}$ \\
\hline & ${ }^{* *}=p<0.001=$ highly significant vs. control subjects. & \\
& $*=p<0.01=$ significant vs. control subjects. &
\end{tabular}

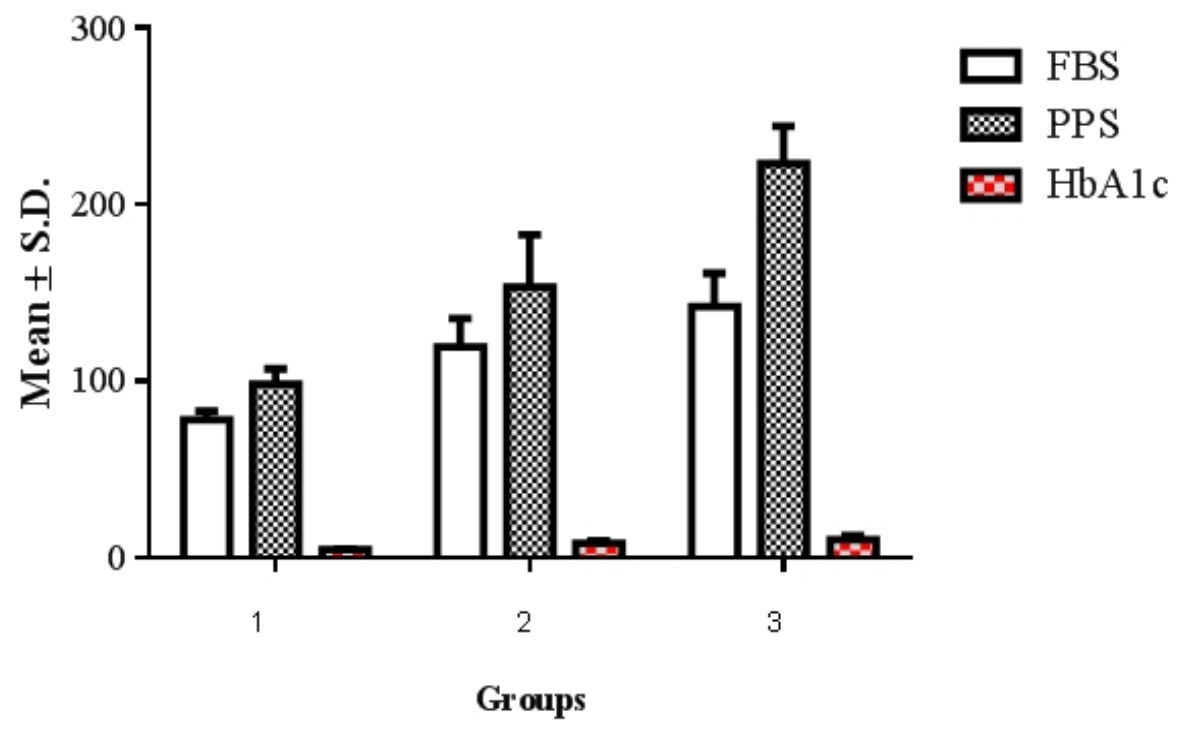

Fig. 1. Mean of FBS, PPS and HbA1 $c$ in control (1), and diabetic groups without retinopathy (2) and with retinopathy (3) respectively 


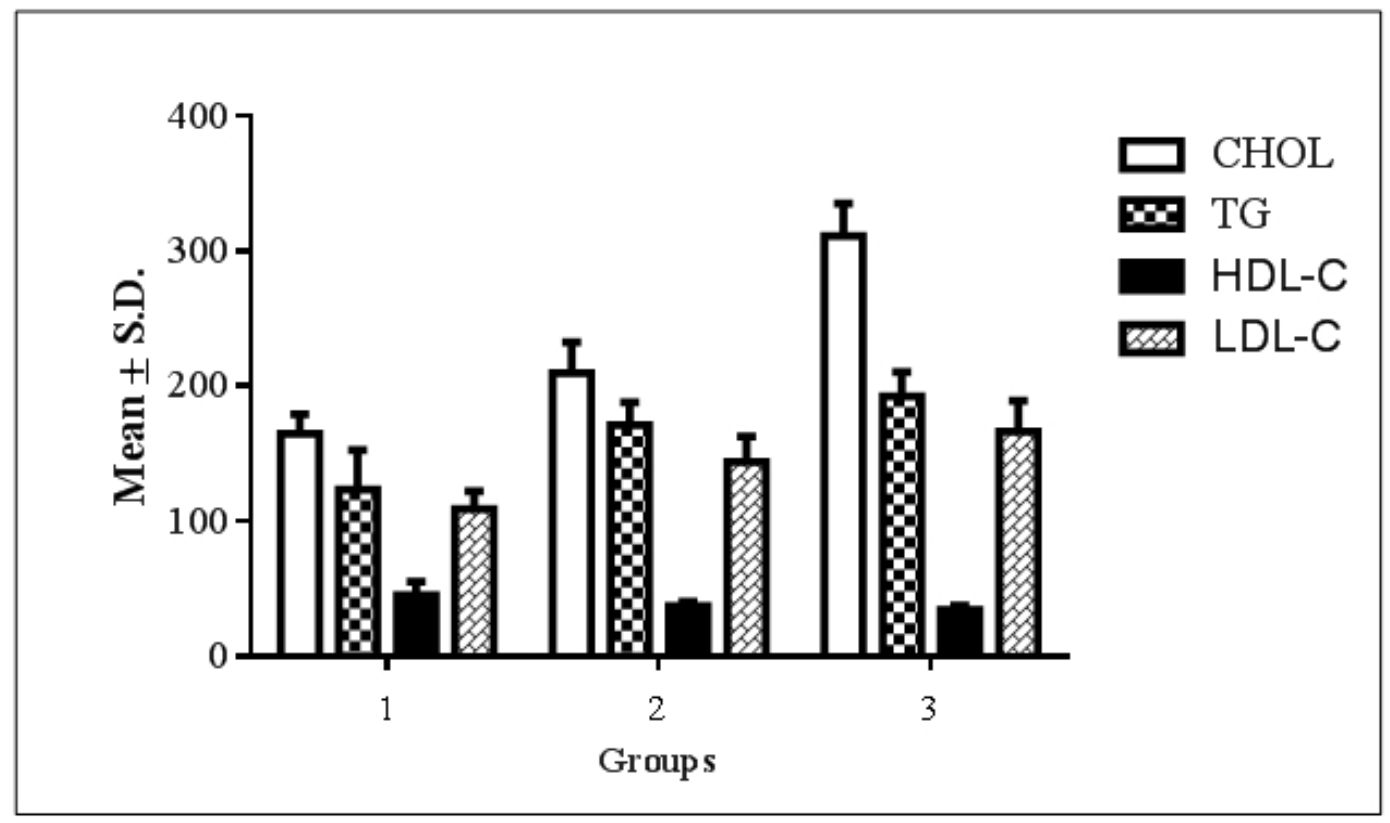

Fig. 2. Mean of total cholesterol, TG, HDL-C and LDL-C in control (1) and diabetic without retinopathy (2) and with retinopathy (3) respectively

\subsubsection{The Arg213 Gly polymorphism of the EC-SOD gene}

Genotype distribution of Arg213Gly EC-SOD polymorphic markers are summarized in Table 2. The last guanosine residue at the $3^{\prime}$ end of the reverse primer, SOD3-231R, displays a mismatch with the original sequence, 5'-CGGCGG-3', close to codon 213 of the EC-SOD gene. This resulted (depending on the sequence) in creation of an Eco 52I restriction site (5'-CGGCCG-3') in the PCR product. If codon 213 was CGG (Arg), a 104-bp PCR product was obtained that yielded two DNA fragments of 23 and $81 \mathrm{bp}$ in size on digestion with Eco52I. In contrast, if codon 213 was GGG (the Gly allele), the 104-bp product was not digested with the enzyme.

The frequency of the Arg213Gly polymorphism of EC-SOD gene was higher in type 2 diabetic patients and highly increased in diabetic patients with retinopathy than that in nondiabetic subjects in the Egyptian population as the Arg/Arg homozygotes were 2 times more frequent than Gly/Gly homozygotes in healthy subjects, but they were nearly equal in diabetic patients, as shown in Fig. 3 and in Table 2. 


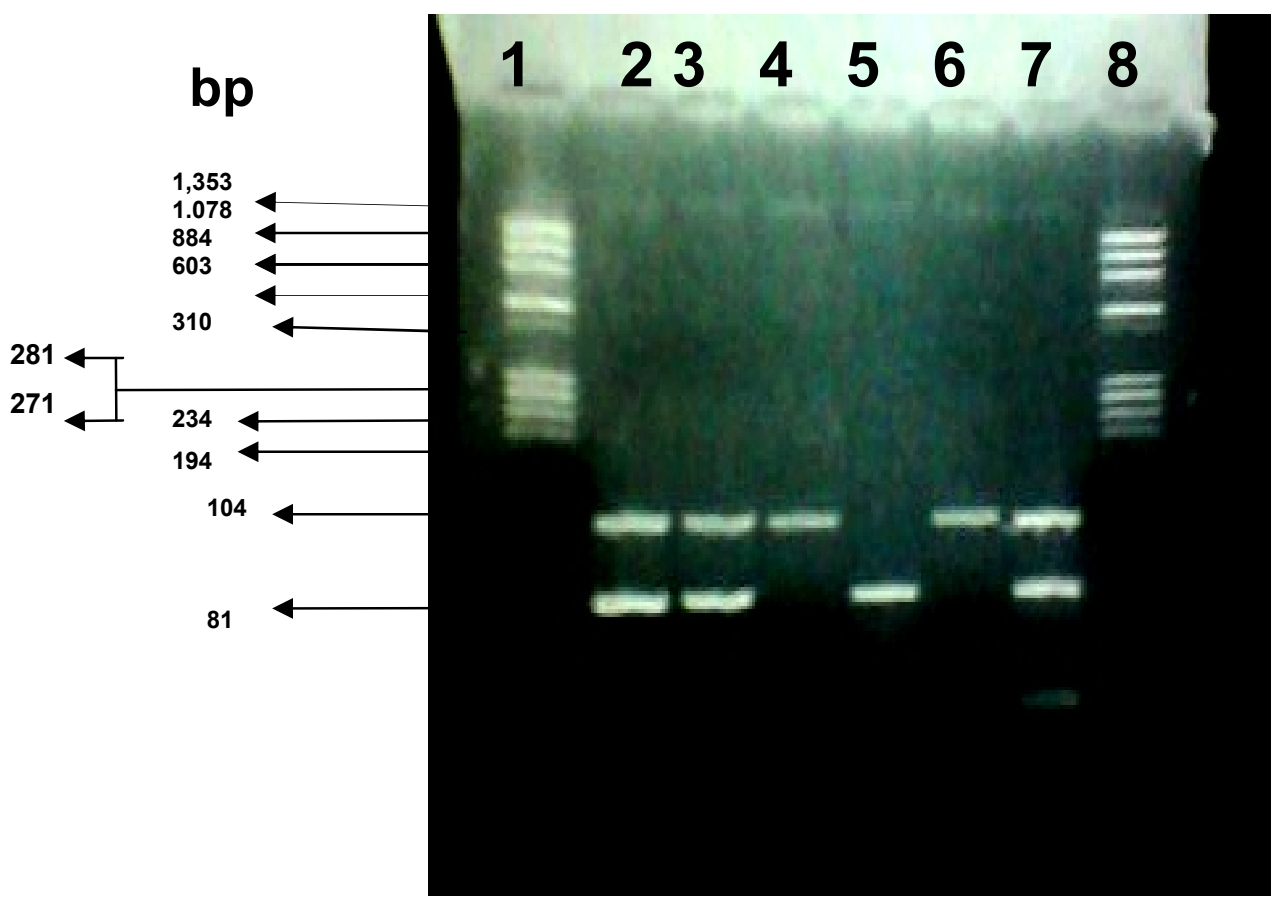

Fig. 3. Restriction analysis of Arg213Gly polymorphism at the SOD3 gene. Lanes 2-7, samples after digestion with Eco521; lane 5, Arg / Arg genotype; lanes 2, 3 \& 7, Arg/Gly genotype; lanes 4 \& 6 Gly/Gly genotype. Lane 1 \& 8: molecular DNA marker $\varphi$ $X 174$ / Hae III fragments are shown.

Table 2. Genotype distribution of the Arg213Gly EC-SOD polymorphic markers in control and diabetic patient groups

\begin{tabular}{llll}
\hline Parameter & \multicolumn{3}{l}{ Genotype frequency $\mathbf{n}(\%)$} \\
\cline { 2 - 4 } Group & Arg/Arg & Arg/Gly & Gly/Gly \\
\hline Control & $6(30)$ & $11(55)$ & $3(15)$ \\
Diabetic without retinopathy & $3(15)$ & $13(65)$ & $4(20)$ \\
Diabetic with retinopathy & $2(10)$ & $14(70)$ & $4(20)$ \\
\hline
\end{tabular}

\subsection{Discussion}

It has been reported that diabetic patients especially in patient with retinopathy have significant defects of antioxidant protections and generation of reactive oxygen species (oxidative stress) which may play an important role in the etiology of diabetic complications $[25,26]$.

The present study demonstrated that diabetic patients with and without retinopathy showed an abnormal lipid profile with a significantly higher serum level of CHOL, TG \& LDLCholesterol and a significantly lower HDL-Cholesterol concentration as compared with the control level. Hypercholesterolemia (CHOL) and hypertriglyceridemia (TG) were mostly observed and related largely to the diabetic retinopathy group. Serum HDL-Cholesterol was reported to be low in diabetic patients with and without retinopathy. In agreement with [27] 
who reported that, hyperglycemia may alter lipoproteins to a form that promotes atherogenesis. LDL -Cholesterol levels was frequently altered in diabetic patients with and without retinopathy.

Moreover, Diabetic patients especially with retinopathy have increased inflammatory markers (ESR\&CRP) which reflected the presence of inflammation and might be a predictor of progression of renal and hepatic diseases [25].

In the present study, oxidative stress was found to be significantly increased in diabetic patients with and without retinopathy compared to the healthy subjects, inconsistent with [7] who reported that, Type 2 diabetes was characterized by increased oxidative stress.

In this work, the enzymatic activity of SOD was significantly decreased in diabetic patients especially in patient with retinopathy, in agreement with [27] and [5] who giving evidence of increased reactive oxygen species production in diabetic patients. The decrease of SOD activity might be attributed to the following reasons: (1) Hyperglycemia activates various biochemical pathways such as glucose autoxidation, nonenzymatic glycation of proteins and activation of protein kinase $\mathrm{C}$, which, in turn, overproduce oxidants like superoxide and hydroxyl radicals as well as hydrogen peroxide. (2) The increase of glycosylated SOD that leads to the inactivation of this enzyme. (3) Loss of its two factors, $\mathrm{Zn}^{2+}$ and $\mathrm{Cu}^{2+}$ [27]. In agreement with the previously study of [26] who stated that, the SOD deficiency may leads to retinal capillary cell death and involved in the pathogenesis of retinopathy in diabetes.

Also this study showed that, the frequency of the Arg213Gly polymorphism of EC-SOD gene was higher in type 2 diabetic patients with and without retinopathy than that in non-diabetic subjects. EC-SOD protein is composed of four domains, which are signal peptide (amino acid residues 1-18), amino-terminal domain (residues 19-95), active site that shows $50 \%$ homology to Cu/Zn SOD (residues 96-193) and heparin binding domain (residues 194222). An Arg213Gly substitution occurs in the center of the carboxyl-terminal cluster of positively charged amino acid residues defining the heparin-binding domain [28].

The substitution of arginine-to-glycine amino acid in the extracellular isoform (EC-SOD) affects the amount of the enzyme on the external endothelial cell surface [29]. This amino acid substitution may result in a higher level of dissociation of the enzyme from the cell surface into serum. Thus, the lower levels of EC-SOD on vascular walls must be positively correlated with a higher risk of progression of oxidative stress in affected patients with the Gly/Gly genotype. The Arg variant of EC-SOD is the most common in various populations [30]. It is predicted that the Arg213Gly substitution alters the secondary structure of proteins, which may affect the localization and transport of the enzyme into external fluid, where it exerts its antioxidative action.

Since EC-SOD is highly expressed in blood vessels, several studies have investigated the role of this enzyme in vascular diseases. On the other hand, [16] has observed a positive correlation between serum EC- SOD levels and the severity of vascular complications, such as retinopathy, nephropathy and an increase in carotid artery intima-media thickness, in type 2 diabetic patients. They conclude that serum EC-SOD levels may be a marker of vascular injury, possibly reflecting decreased binding of EC-SOD to the vascular wall. Understanding the role of MnSOD to modify the course of retinopathy could elucidate important molecular targets for future pharmacological interventions [26]. 


\section{CONCLUSION}

In conclusion, the present data revealed that hyperglycemia produced marked oxidation impact that may play an important role in the development of complications in diabetic patients, as evidenced by a significant increase in lipid profile, lipid per oxidation products, as well as a significant decrease in the total SOD activity. Moreover the presented findings showed that the genotype distribution of the EC-SOD in diabetic patients with and without retinopathy can differed from nondiabetic individuals, as the arginine-to-glycine amino acid substitution is higher in diabetic patients with and without retinopathy than control persons. The results of this study suggest a protective role for SOD in retinal capillary cell death and, ultimately, in the pathogenesis of retinopathy in diabetes.

\section{ACKNOWLEDGEMENT}

The authors would like to express their gratitude and deepest appreciation to all staff members of Department of Internal Medicine \& Clinical Pathology Department - Molecular Biology Unit, Al-Hussein Hospital, Al-Azhar University, Cairo, Egypt, for their sincere cooperation.

\section{COMPETING INTERESTS}

Authors have declared that no competing interests exist.

\section{REFERENCES}

1. Seghrouchni I, et al. Oxidative stress parameters in type I, type II and insulin-treated type 2 diabetes mellitus; insulin treatment efficiency. Clinica Chimica Acta. 2002;321:89-96.

2. Kumar, Vinay, et al Robbins and Cotran Pathologic Basis of Disease (7th ed.). Philadelphia, Pa.: Saunders. 2005;1194-1195. ISBN 0-7216-0187-1.

3. Risérus $U$, Willett WC, Hu FB. Dietary fats and prevention of type 2 diabetes. Progress in Lipid Research. 2009;48(1):44-51.

4. Ripsin CM, Kang H, Urban RJ. Management of blood glucose in type 2 diabetes mellitus. Am Fam Physician. 2009;79(1):29-36. PMID 19145963.

5. Flekac $M$, et al. Gene polymorphisms of superoxide dismutases and catalase in diabetes mellitus. BMC Medical Genetics. 2008;9:30.

6. Pardianto $G$, et al. Understanding diabetic retinopathy. Mimbar IImiah Oftalmologi Indonesia. 2005;2:65-6.

7. Basel, Karger. Causes and Risk Factors. Diabetic Retinopathy(USA). 2010: 20:1-19.

8. Fong D, Stern MP, Pugh JA, Hazuda HP, Patterson JK, van Heuven WA, Klein R. Diabetic retinopathy in ... S84 Diabetes Care. 2004;27(suppl 1 s84-s87).

9. Kertes PJ, Johnson TM, ed. Evidence Based Eye Care. Philadelphia, PA: Lippincott Williams \& Wilkins; 2007: ISBN 0-7817-6964-7. [page needed]

10. Tapp RJ, Shaw JE, Harper CA, et al. The prevalence of and factors associated with diabetic retinopathy in the Australian population. Diabetes Care. 2003;26(6):1731-7. doi:10.2337/diacare.26.6.1731. PMID 12766102.

11. Adachi $T$, et al. Relationship of plasma extracellular-superoxide dismutase level with insulin resistance in type 2 diabetic patients. Journal of Endocrinology. 2004;181:413417. 
12. Varachaud $A$, et al. Variable expression of $M n S O D$ in three different human melanoma cell lines. Eur J Dermatol. 1998;8(2):90-94.

13. McCord J. M, Fridovich I. Superoxide dismutase. An enzymic function for erythrocuprein (hemocuprein). J. Biol. Chem. 1969;244:6049-6055.

14. Folz RJ, et al. Mouse Extracellular Superoxide Dismutase: Primary Structure, Tissuespecific Gene Expression, Chromosomal Localization, and Lung In Situ Hybridization. Am. J. Respir. Cell Mol. Biol. 1997;17:393-403.

15. Tamai $\mathrm{M}$, et al. Extracellular superoxide dismutase gene polymorphism is associated with insulin resistance and the susceptibility to type 2 diabetes. Diabetes Research and Clinical Practice. 2006;71:140-145.

16. Kimura F, Fukui M, et al. Serum Extracellular Superoxide Dismutase in Patients with Type 2 Diabetes: Relationship to the development of micro- and macrovascular complications. Diabetes Care. 2003;26:4.

17. Nozik-Grayck E, Suliman HB, Piantadosi C. A. Molecules in focus: Extracellular superoxide dismutase. The International Journal of Biochemistry \& Cell Biology. 2005:37:2466-2471.

18. Viswanath, Murray McGavin DD. Diabetic Retinopathy: Clinical Findings and Management. 2003;16(46):21-24.

19. Friedewald WJ, Levy RJ, Fredrickson DS. Estimation of the concentration of lowdensity lipoprotein cholesterol in plasma without use of the preparative ultracentrifuge. Clin Chem. 1972;18:499-502.

20. Trivelli LA, Ranney HM, Lai HT. New Eng. J. Med. 1971;284:353.

21. Westergren A. Studies of the suspension stability of the blood in pulmonary tuberculosis. Acta Med Scand. 1921;54:247-282.

22. Charles Wadsworth, et al. Clinica Chimica Acta. 1984;138:309-318.

23. Minami M, Yoshikawa HA. simplified assay method of superoxide dismutase activity for clinical use. Clin Chem. Act. 1979;92:337-342.

24. Chistyakov DA, et al. Polymorphisms in the Mn-SOD and EC-SOD genes and their relationship to diabetic neuropathy in type 1 diabetes mellitus. BMC Medical Genetics. 2001;2:4.

25. Opara EC. Oxidative stress, micronutrients, diabetes mellitus and its complications. J. R Soc Health. 2002;122(1):28-34.

26. Kowluru RA, Kanwar M. Oxidative stress and the development of diabetic retinopathy: Contributory role of matrix metalloproteinase-2. Free Radical Biology \& Medicine. 2009 46:1677-1685

27. Abou-Seif MA, Youssef A. Evaluation of some biochemical changes in diabetic patients. Clinica Chimica Acta. 2004;346:161-170.

28. Sandstrom J, et al. 10-fold increase in human plasma extracellular superoxide dismutase content caused by a mutation in heparin-binding domain. J Biol Chem. 1994;269:19163-19166.

29. Adachi $\mathrm{T}$, et al. Substitution of glycine for arginine-213 in extracellular-superoxide dismutase impairs affinity for heparin and endothelial cell surface. Biochem $\mathrm{J}$. 1996;313:235-239. 
30. Yamada $\mathrm{H}$, et al. Molecular analysis of extracellular-superoxide dismutase gene associated with high level in serum. Jpn J Hum Genet. 1995;40:177-184.

(c) 2013 Sayed et al.; This is an Open Access article distributed under the terms of the Creative Commons Attribution License (http://creativecommons.org/licenses/by/3.0), which permits unrestricted use, distribution, and reproduction in any medium, provided the original work is properly cited.

Peer-review history:

The peer review history for this paper can be accessed here: http://www.sciencedomain.org/review-history.php?iid=205\&id=12\&aid=1197 